\title{
The Impact of Interest Rate Volatility on Stock Returns Volatility: Empirical Evidence from Pakistan Stock Exchange
}

\author{
ARIF HUSSAIN \\ Assistant Professor, Institute of Business and Leadership \\ Abdul Wali Khan University Mardan \\ arifhussain@awkum.edu.pk \\ AHMAD BILAL HUSSAIN \\ Lecturer, Northern University, Nowshehra \\ Abhussain0404@gmail.com \\ SHAHID ALI \\ PhD Scholar-Institute of Business Studies and Leadership \\ Abdul Wali Khan University Mardan \\ shahidali@awkum.edu.pk
}

\begin{abstract}
Apprehension pertaining to Stock return volatility always has been producing the appreciable significance in the various current research works and it has been lucrative to many researchers for forecasting stock market volatility. This study is about the forecasting of stock returns volatility on the basis of interest rate volatility in the well established Pakistan Stock Exchange (PSX). The stock returns are calculated on the basis of KSE 100 index and interest rate volatility is calculated on the basis of monthly treasury bills rate during a period of 1994 to 2016. Various volatility models like Auto Regressive Conditional Heteroscedasticity (ARCH) and Generalized Auto Regressive Conditional Heteroscedasticity (GARCH) were used to predict stock return volatility on the basis of interest rate volatility in Pakistan. ARCH model is one of the well known methods to forecast the error term in the data and which will certain our forecast regarding stock prices. In the Pakistan Stock Exchange the ARCH $(1,1)$ has been statistically significantly proved. The GARCH $(1,1)$ model is also used to estimate the stock volatility. This model shows the short run volatility affect the lagged stock returns and is contributing to the overall volatility. The sum of $\alpha$ and $\beta$ is less than 1 so the short run volatility is positively related to the overall stock volatility. The $\operatorname{GARCH}(1,1)$ model has outperformed the other volatility models in the case of Pakistan Stock Exchange.
\end{abstract}

Key Words: Interest rates volatility, Stock Return Volatility, ARCH, GARCH

\section{Introduction}

The Subsistence of a well regulated and well organized stock exchange is very much significant for the gentle functioning of the financial markets in any country. As the stock market accommodate appropriate platform for the trading of securities and also allure savings from the public. The expected and unexpected changes of the stock market 
activities provoke the investors to redesign or take decisions regarding their investment portfolios in the short run and in the long run. The apprehension of such a phenomenon is so much vital for the emerging stock market like the Pakistan Stock Exchange (PSX). The PSX has noticed appreciable amount of changes in the last few years since its incorporation. The major query is as to what drives the Pakistan Stock Exchange and what are the provoking factors for such transparent changes. The answer is not much simple as the Pakistan Stock Exchange show a very complicated behavior over the period of time. In the early $90 \mathrm{~s}$ the liberalization and deregulation of the economy and institutions permitted the foreign investors and private sector in the country to direct their funds towards the stock markets in Pakistan. Such contribution ascertained the higher trading volumes and also result in the increase of market capitalization to a greater extent. The period of mid 90s has proved a nightmare for the PSX because of the political unrest and deteriorating law and order situation in the country. The nuclear test has further aggravated the situation in the form of economic sanctions from the entire world. The period of 2000 to 2007 is considered to be the honey moon period for the Pakistan Stock Exchange as the market has observed appreciable amount of growth in capitalizations and also in the volume turnover. Such a performance of PSX can be attributed to the positive growth favoring strategies, a highly stable and continuous macroeconomic policies, stability at the political fronts, the higher liquidity in the market, inflow of the foreign investments, a flourishing amounts of corporate earnings and also the privatization of most of the public sector corporations has put the PSX towards prosperity. A common observation about PSX assumes that it is much driven by the speculative measures, insider trading and also the price manipulation by the major investors in the market rather than by the investment oriented fundamental factors in the market.

Various efforts have been made to explore the dynamics and mysteries of the stock market movements and variations. The financial market integration, adjustment of stock market to the origination of new information, the market fundamentals and various macroeconomic policy changes are a few factors which directly or indirectly may affect the stock market activities and their trends. The question as to what moves the stock markets and what can be the underlying factors for the stock market volatility and its movements are much important than how to quantify them. The present is regarding the impacts of interest rates on the stock prices and their volatilities in the Pakistan Stock Exchange.

\section{Literature Review}

Zafar et al. (2008) investigated the influence of short term interest rates on the stock return volatility in Pakistan during 2002- 2008. The GARCH models were applied to assess this relationship. Conclusions came up with finding that the short term interest rates have a great predictive power to assess the stock returns as a strong negative relationship has been confirmed in the particular study. Likewise Poon and Tong (2009) has confirmed a weak predictive power of the movements in various variables like interest rate, growth output and the inflation rate with that of stock returns.

Mala and Reddy (2007) has studied the Fiji stock market and its movements because of interest rates changes. By using ARCH and GARCH models it was confirmed that interest rate changes have a significant effect on the stock returns and their 
volatilities in the small island economy of Fiji. Leon (2008) has explained the dynamics of interest rate, stock returns and the stock returns volatility. The GARCH models were applied on the data of time series regarding interest rates and stock returns. The results confirmed a tight nexus between stock return and interest rates. On the other hand, the interest rate has a weaker predictive ability to determine the volatility in the Korean Stock Market.

Joseph and Vezos (2006) has studied collectively the combined effects of interest rates and foreign exchange rates changes on the stock returns of banking firms in the United States. The EGARCH model and simple ordinary least square (OLS) regression models were applied in this context. It has been confirmed that the foreign exchange rate and interest rate sensitivity does not reflect the stock return sensitivity for the United States banking firms as is shown by the empirical results. While the stock market index returns to a greater extent lead to stock return sensitivity of banking firms in the United States markets.

Beirne et al. (2009) studied the impacts of exchange rate and interest rate on the stock returns of financial sector in sixteen countries of Europe, Japan and the United States. A strong negative effect of the said variables on the stock returns has been confirmed. Elyasiani (2004) in a study of interest rate movements and the stock returns has asserted that interest rate do affect the banking firm's stock returns in the United States financial market. The sensitivity of insurance company's stock returns to that of interest rate variations in the United States markets has been studied by Brewer et al (2006). By using the GARCH-M model a strong form of sensitivity was determined between interest rate and insurance company's stock returns in the United States markets. According to Rizwan and Khan (2007) the short term interest rates confirms the stock returns movements in the KSE.

\section{Methodology}

This research is an empirical study on the relationship of interest rate with that of KSE100 index and predicting the stock index (KSE100 index) volatility based on Interest rates volatility. Data for this research was collected from different sources. KSE 100 index was collected from the PSX website, while the monthly T-bills rate was collected from IFS software and state Bank of Pakistan for the period of 1994 to 2016. The main theme of this paper is to predict the implied stock volatility of Pakistan Stock Exchange (PSX) while using different volatility models. So the universe of the study is the Pakistan Stock Exchange. Sample of the study is KSE100 index which is the representative index of the Pakistan Stock Exchange. Stock prices and monthly T-bills rate were taken into consideration for the statistical computation and analysis. Various volatility models like Auto Regressive Conditional Heteroscedasticity (ARCH) and Generalized Auto Regressive Heteroscedasticity (GARCH) were used to predict stock return volatility on the basis of interest rate volatility in Pakistan. ARCH and GARCH models are one of the well known methods to forecast the error term in the data. 


\subsection{Empirical Analysis}

\subsubsection{Autoregressive Conditional Heteroskedocity (ARCH)}

Autoregressive conditional heteroscedasticity $(\mathrm{ARCH})$ is used to predict the error term or volatility in the time series data. In $\mathrm{ARCH}$ it is assumed that variance of error term depends on the real size of the previous periods residual terms.

The following method is used stepwise to find ARCH in the data as given below.

1) As first step a simple regression is estimated between monthly stock returns as dependent variable and monthly interest rate as independent variable.

2) Residuals from the regression output of the first step are saved. Another regression is estimated between the differenced stock returns as dependent variable and residual term as independent variable with various lagged values. The lagged value is selected where the output of uhat is significant.

3) The square value of the residual term is again regressed on its various lagged values and the significant lagged value is selected from the regression estimates.

The above mentioned procedure of ARCH is mentioned in the following equations.

\section{ARCH (1)}

\begin{tabular}{lc}
\hline Stockreturns $=$ & $69.2227+1.13651$ T-bills rates ------- Equation 1 \\
\hline t-Value & $1.6382 \quad 20.8406$ \\
R-squared & 0.984539 \\
F & 1979.980 \\
\hline d_Stock_returns $=45.4975+$ uhat - ----------------------- Equation 2 \\
\hline t-value $\quad 5.7699$ & 66.3800 \\
R-squared & 0.957621 \\
F & 4406.304 \\
\hline
\end{tabular}

\begin{tabular}{|c|c|}
\hline t-value & $\begin{array}{ll}6 & 2.5805\end{array}$ \\
\hline R-squared & 0.030602 \\
\hline $\mathrm{F}$ & 6.103500 \\
\hline
\end{tabular}

Equation 1 shows the regression estimates where the monthly stock returns are taken as dependent variable and monthly interest rate as independent variable. Output of the regression estimates show that the estimated coefficient of interest rate has a significant positive relationship with stock returns. The F-value is also significant which shows the significance of the model as a whole. The R-Square value of $98.45 \%$ shows 98\% variations in stock returns are due to due to interest rate in Pakistan. Equation 2 shows result of regression where the error term or residual term is regressed against the lagged stock returns. The t-value and F-statistics values are found to be significant. Equation 3 shows regression estimates where square of the residual term is regressed on various lagged values and selected the lagged value which is significant. The square of the residual term is found significant at first lag. It is therefore concluded that in case of stock returns in the Pakistan Stock Exchange and short term T-Bills rate (interest rate) 
there exist ARCH. Square of the error term shows stock return volatility and depends on the lagged square values of the residual terms.

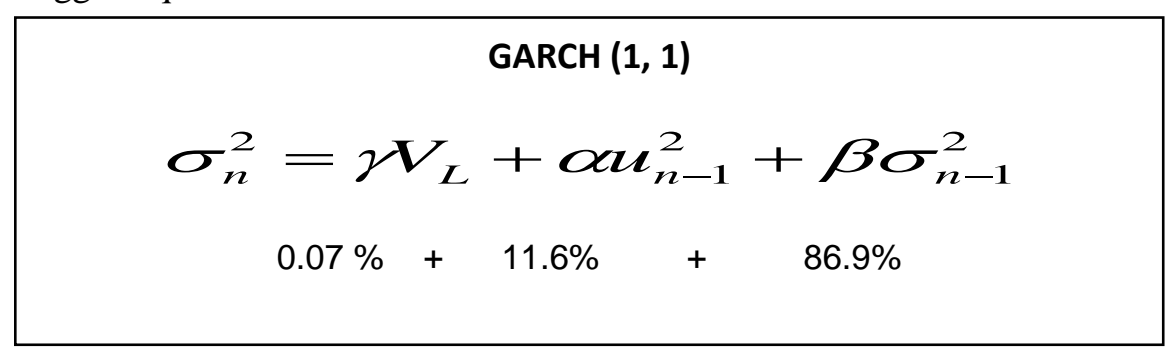

\subsubsection{GARCH(p,q), Generalized Autoregressive Conditional Heteroskedocity}

Generalised autoregressive conditional heteroscedasticity (GARCH) model is also used for the estimation of stock returns volatility on the basis of changes in interest rates in Pakistan. The variance equation in the model shows that square of the previous residuals have appositive and significant on the volatility of stock returns. The past variances have also a positive and significant impact on the volatility stock returns. There is $7 \%$ short term volatility in the above mentioned GARCH model. The lagged stock returns contribute in the total volatility by $11.5 \%$, while the variance contribution in the total volatility is $86.8 \%$. The sum of $\beta$ and $\alpha$ is $97.7 \%$ which lower than 1 . It is therefore concluded that short term volatility has positive association with the overall volatility of stock returns.

\section{Conclusion}

In the entire risk assessment of stocks the volatility of stock returns and interest rates is crucial. This nexus is crucial in the implementation of monetary policy and risk management practices of financial institutions. Different theories established that an inherent relationship exists between the interest rate and stock returns. This study has a greater emphasis on the forecasting of volatility of the stock returns based upon the volatility of the interest rates. The data has been taken from the well established Pakistani Stock Exchange, KSE 100 Index and monthly treasury bills rate from 1994 to 2016. Different models have been brought in use for estimating stock volatility. The first model which has been brought in use is ARCH Model which is very popular model for forecasting the error term in the data and which will certain our predictions related to stock prices. It has been proved that the ARCH $(1,1)$ is statistically significant in PSX. The second model which has been brought in use is $\operatorname{GARCH}(1,1)$ for the estimation of volatility of the stocks. The lagged stock returns are affected by the volatility in the short run ultimately contributing to the entire volatility. The sum of $\alpha$ and $\beta$ is less than 1 so the short run volatility is positively related to the overall stock volatility. In case of Pakistan Stock Exchange the GARCH $(1,1)$ model has outperformed the other volatility models.

\section{References}

Beirne, J., Maria, G. \& Spagnolo, N. (2009). Market, Interest rate and exchange rate risk effects on financial stock returns: A GARCH-M approach. Quantitative and Qualitative Analysis in Social Sciences, Vol 3(2), pp 44-68. 
Brewer, E., Carson, M., Mansur, I. \& Scott, W. (2006). Interest rate risk and equity values of life insurance companies: A GARCH-M model. Journal of Risk and Insurance.

Elyasiani, E. (2004). Bank stock returns sensitivities to the long-term and short-term interest rates: A multivariate GARCH approach. Managerial Finance, Vol. 30(9)

Joseph, N. \& Vezos, P. (2006). The Sensitivity of US Bank's Stock Returns to Interest Rate and Exchange Rate Changes. Managerial Finance, Vol 32, No.2, pp 182199.

Leon, N. K. (2008). The Effects of Interest Rates Volatility on Stock returns and Volatility: Evidence from Korea. Euro Journal of Finance and Economics, 14, pp. 285-290.

Mala, R. \& Reddy,M. (2007). Measuring stock Market Volatility in an Emerging Economy. International Research Journal of Finance and Economics, Issue 8.

Rizwan, M. \& Khan, S. (2007). Stock return volatility in emerging equity market (KSE): The relative effects of country and global factors. International Review of Business Research Papers, Vol.3(2), pp 362-375.

Zafar, N., Faiza,S. \& Khan, T. (2008). Interest Rate Volatility and Stock Return and Volatility. European Journal of Economics, Finance and Administrative Sciences, Issue 14. 